\title{
BANGER-RELATED OCULAR INJURIES DURING NEW YEAR FESTIVITIES IN OSOGBO, SW NIGERIA
}

\author{
Adeoti $\mathrm{CO}^{1}$, Isawumi MA ${ }^{1,2}$, Onakpoya $\mathrm{OH}^{3}$, Agbeleye DS ${ }^{1}$
}

\begin{abstract}
BACKGROUND: Different types of ocular injuries could be sustained following banger explosives. This case report could be the first of such reports in West Africa.

CASE DETAILS: We report cases of ocular injuries caused by bangers. This was a hospital-based study of 3 consecutive cases that presented during the New Year festival. Injuries were classified according to Birmingham eye trauma terminology system (BETTS). Two of the patients ended up with irreversible loss of vision. Another two of the three were bystanders.

CONCLUSION: As banger-related ocular injuries result in significant morbidity, public education regarding the proper use of bangers would help in preventing the incidence of ocular injuries and blindness. Advocacy for a strict legislation to regulate its use is strongly recommended.

KEYWORDS: Bangers, eye injuries, holidays, Nigeria
\end{abstract}

DOI: http://dx.doi.org/10.4314/ejhs.v25i2.12

\section{INTRODUCTION}

Bangers are simple fireworks consisting of rolled paper tubes filled with gunpowder. The tubes which are made of heavy paper casing also have a fuse at the top (1). The banger is lit and then thrown. After a short pause, it explodes with a loud bang. Other forms of fireworks include Jumping Jacks, Chinese Crackers, Aerial shells and Bird scaring explosives also called rookies and deer scarers (2).

Bird-scaring explosives, or bangers, are now being modified and used as fireworks in bonfire night celebrations (3). In different places across the world, these bangers and other explosives are used during celebrations and holidays. Examples are the holidays of Idel Adhab among the Arab and Druze population, the Jewish Purim festival in Israel (4), and the Indian Deepavali festival, where firecrackers are often used traditionally during the celebration (5). In all of these, multiple injuries including eye injuries usually occur $(4,5)$. There have been several other documented literatures concerning ocular injuries following the use of fireworks mostly in the developed countries $(6,7)$.

Following experiments, the mechanisms of fireworks injuries have been suggested to possibly follow missiles or projections, pressure and heat from the exploded fireworks especially when close to the eye $(8,9)$. Various types of injuries such as adnexal, globe rupture and burns could occur following the explosion of these bangers (10). Injuries could be caused by blunt or sharp objects $(6,11)$. Any part of the eye, be it adnexal or ocular structures, could also be affected $(12,13)$.

Ocular injuries, types and their sequelae sustained from bangers during festivities have been reported in South Africa $(14,15)$, but are yet to be reported in West Africa. We hereby report the first series of cases of ocular injuries caused by bangers in Nigeria. Ethical approval was obtained from LAUTECH Teaching Hospital Research and Ethical Committee.

\footnotetext{
${ }^{1}$ Ladoke Akintola University of Technology Teaching Hospital, Osogbo, Osun State, Nigeria

${ }^{2}$ College of Health Sciences, Osun State University, Osogbo, Nigeria

${ }^{3}$ Obafemi Awolowo University Teaching Hospital, Ile Ife, Osun state, Nigeria

Corresponding Author: Michaeline A Isawumi, Email: misawumi@gmail.com
} 


\section{CASE REPORTS}

\section{CASE 1}

A 20-year old trader presented with a 30-minute history of firework injury on the left eye. He had a passive role as he was seated in his shop when the explosive was thrown in, exploding in his left eye. Pre-morbid vision was said to be good. Presenting visual acuity (PVA) in each eye was 6/9. On examination, he had mild lid edema, mild hyperemia with subconjunctival hemorrhage, clear cornea, anterior chamber cells grade 3, sluggish pupils, clear lens and normal fundus. Right eye (RE) was grossly normal. Intraocular pressures were $10 \mathrm{mmHg}$ each eye.

The patient was commenced on steroidantibiotic and cycloplegic eye drops, antibiotic ointment at night and non-steroidal antiinflammatory tablets. On the $3^{\text {rd }}$ day, the lid swelling and conjunctiva hyperemia cleared with no anterior chamber reaction. The injury was classified as contusion injury with no ocular wall damage either by penetration or laceration.

\section{CASE 2}

A 17-year old male student presented with 8 days history of pain and loss of vision following banger injury to the left eye which was sustained while throwing the banger. Pre-morbid vision was good. On examination, PVA was no perception of light (NPL). There was blepharospasm, photophobia, ciliary injection, hazy cornea, and total hyphaema. No further structure was seen beyond (Figure 1). Intraocular pressures (IOP) measured $36 \mathrm{mmHg}$ in the left eye and $14 \mathrm{mmHg}$ in the right eye. The patient was admitted and nursed in Fowler's position. Drug treatment included timolol, and dorzolamide eye drops (Trusopt) to reduce intraocular pressures; steroidal anti inflammatory and long acting cycloplegic (atropine) eye drops. He had paracentesis and anterior chamber washout done on the $2^{\text {nd }}$ day. There was mild corneal oedema with haemosiderin stain; the iris was visible, and a small clot hyphaema was left in the pupillary axis. IOP measured $15 \mathrm{mmHg}$ in the last follow-up. He was discharged within 1 week after operation. VA at discharge was NLP. The injury was classified as a contusion injury following a blunt trauma with no ocular wall damage (penetration or laceration).

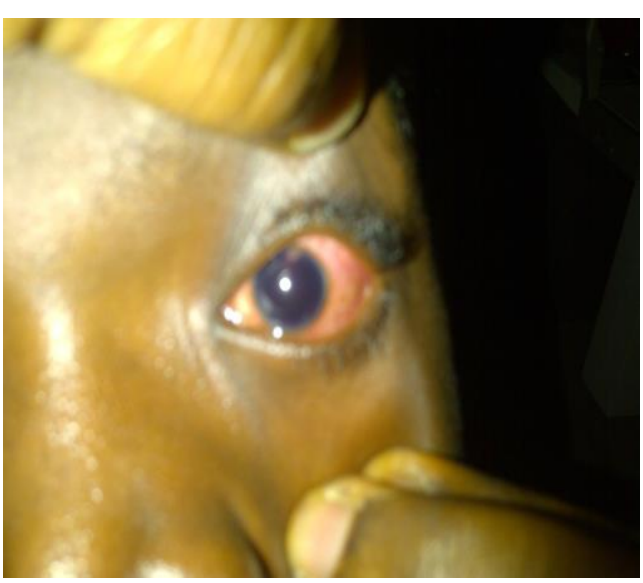

Fig 1: Figure showing black ball hyphaema in the left eye with obliteration of iris and pupil.

\section{CASE 3}

A 12-year old male child presented with a 9 day history of loss of vision in the left eye following a banger injury sustained as a passerby when returning from mosque on a New Year eve. There was immediate bleeding from the inferior lid margin and the eyeball, with associated loss of vision at the time of injury. On presentation, there was associated redness and purulent discharge from the eyeball. Examination revealed VA of NLP, small eye, peri-orbital hyperpigmentation with scars, absent lashes on inferior lid margin with only a few on the superior lid margin, mucopurulent discharge, mild diffuse conjunctival hyperemia, lacerated dirty cornea and uveal prolapse (Figure 2 ). Ultrasound confirmed a shortened axial diameter of $18 \mathrm{~mm}$, disrupted anterior eye wall with reduced corneal thickness and shallow anterior chamber. Conjunctival swab was taken and sent for microscopy, culture and sensitivity (mcs). The injury was classified using BETTS as a perforated globe from blunt injury. Ciprofloxacin eye drops during the day and chloramphenicol eye ointment at night were commenced. Daily dressing with patching was done. The mucopurulent discharge cleared and a left evisceration with a silicone implant was done 4 days later. The result of the ' $\mathrm{m} \mathrm{c}$ s' yielded growth of Staphylococcus aureus sensitive to the antibiotics used. The patient was discharged on the $4^{\text {th }}$ post operative day on eye dressing, antibiotic eye drops and ointment but was later lost to follow-up. 


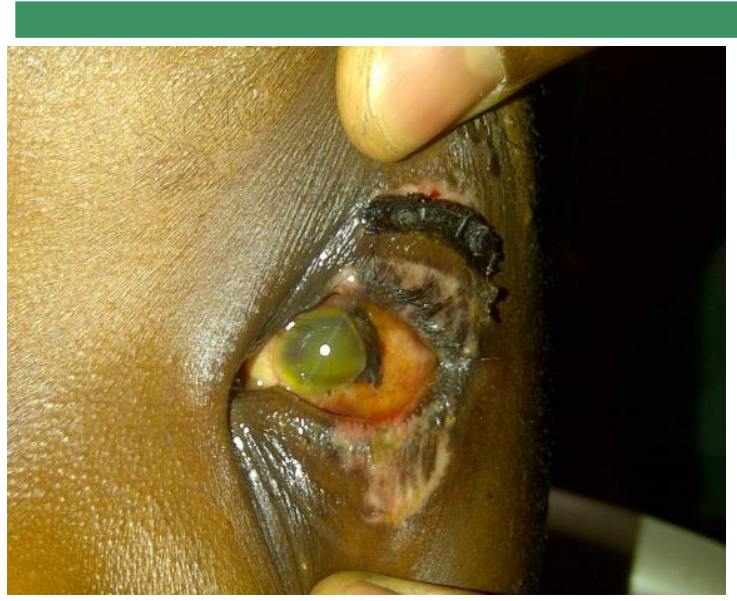

Fig 2: Figure showing hypopigmentations from burns and loss of lower lid eye lashes, ruptured globe, uveal prolapse and smaller eyeball size in the left eye

\section{DISCUSSION}

Fireworks injuries are common occurrences all over the world either following festivities or holidays (4, 5). In Nigeria, fireworks are commonly used during the Christmas and New Year holidays.

This study revealed that these injuries occurred during the New Year festival as similarly reported by others that such injuries occur during festivities in Israel, India and Iran (Persian festival), $(4,5,10)$. It should be noted, however, that no injury was sustained in other parts of the body apart from the eye and adnexae. The ages of the injured in this study ranged between 12 and 20 years. This is similar to other studies where children and youths were found to be most affected. In china, children below the age of 15 years made up $63 \%$ of cases (10), while in India, individuals aged less than 20 years made up $60 \%$ (5). This is not unexpected because it is the youth who are normally very active and would usually be seen to be either actively or passively participating in these activities.

All the affected individuals were males $(100 \%)$. Similar studies in South Africa, China and India have shown male preponderance in more than $65 \%$ of cases $(14,16,17)$.

Case 1 had a presenting visual acuity of 6/9 of all three cases. It is possible that the impact was not much so that a very mild effect on the ocular tissues resulted. A study showing the mechanisms and impact of injury via missile projection, pressure and heat has been tested experimentally to be true (8). An early presentation of within 30 minutes, coupled with prompt treatment given, absence of endophthalmitis and closed globe injury also led to good visual outcome. A similar good visual outcome was seen in a study carried out in India which also had these characteristics (17).

This patient also had lid oedema, conjunctival hyperemia, sub-conjunctival haemorrhage and hyphaema. These signs resolved spontaneously following admission and conservative management. Similar studies had documented associated lid and adnexal involvement following fireworks injuries $(13,18)$.

Case 2 had a contusion injury, presented late and with VA of NLP. He had corneal haze, a total hyphaema with raised intraocular pressure. Paracentesis and anterior chamber washout was done. The vision still remained NLP despite surgical intervention. This is probably because the raised intraocular pressure over one week had caused damage to the optic nerve. The optic nerve could also have been directly traumatized. The study in India revealed that lid, conjunctiva and corneal lacerations were recorded similar to our findings (2). Similar outcome was noticed amongst the admitted cases in India where the visual acuity was found to be between $<20 / 200$ to light perception (5).

Case 3 was that of a ruptured globe with uveal prolapse which required evisceration. There was also a delay in presentation leading to infection of the eyeball. Several other studies have demonstrated interventional treatments such as anterior chamber washout, corneal repair and enucleation $(5,6,13,14)$. This also revealed the capability of these banger injuries resulting in cosmetically unacceptable appearance. Carrying out the evisceration was necessary to restore facial and ocular aesthetics to the patient but with loss of vision. This would make him socially presentable in the society, among his peers and also to his future suitor.

All three cases required admission. Comparatively, between $25 \%$ to $60 \%$ of cases were admitted in other studies $(5,16,17)$. These may have been due to the large number of cases seen in the study.

The patients in cases 2 and 3 were bystanders as they played passive roles during the festivities. 
This shows that closeness to the area of explosion of bangers or any other form of fire cracker is dangerous. The explosions tend to be released as missiles, and so, can hit anybody within the vicinity. Other studies have recorded similar ocular injuries among bystanders $(5,16)$.

Ocular complications were seen to have reduced in cases where strict restrictions or enforcement of the law occurred (13). This highlights the fact that legislations and law enforcement are necessary in Nigeria. This may help to reduce associated ocular morbidity from these agents of injuries during festivities in the country.

In this study, all the affected persons were youths. There is the possibility of the danger of not taking care of the only eye. The parents, guardians and family members must be educated on the importance of making sure that the child with an only-eye sees an ophthalmologist at least three times a year, and wears constant protective glasses against any dangerous missile or agent to the eye. The advice of the Deutch Society of Ophthalmologist (NOG) that protective polycarbonate glasses be worn while lighting and watching of fire-works is also advocated (7).

Banger-related ocular injuries result in significant ocular morbidity and unilateral visual loss. Public education regarding proper use of bangers along with strict legislation regulating their use would help in reducing the incidence of ocular injuries.

The limitation in this study involves dearth of comparable studies within Nigeria, Africa and other parts of the world.

\section{REFERENCES}

1. Definition of banger by the Free dictionary. In: The American Heritage ${ }^{\circledR}$ Dictionary of the English Language, $4^{\text {th }}$ Ed copyright (C2000. Houghton Mifflin Company, 2009. Website: http://www.thefreedictionary.com/banger. Last accessed $12^{\text {th }}$ of January 2015.

2. Bangers, Chinese Crackers and Aerial shells. UK. Firework. Website: https://www..fireworkreview.org.uk/bangers-chinese-crackers-aerialshells. Last accessed 12th January 2015.

3. Pringle E, Eckstein MB, Casswell Ag, Hughes EHk. New firework caused severe eye injuries at a public display. $B M J, 2012 ; 1: 345$.

4. Zohar Z, Waksman I, Stolero J, Volpin G, Sacagiu E, Eytan A. Injury from fireworks and firecrackers during holidays. Harefuah, 2004; 143(10):698-701, 768.

5. Kumar R, Puttanna M, Sriprakash KS, Sujatha Rathod BL, and Prabhakaran VC. Firecracker eye injuries during Deepavali festival: A case series. Indian J Ophthalmol, 2010; 58(2): 157-159.

6. Kuhn FC, Morris RC, Witherspoon CD, Mann L, Vester V, Mordis L. Serious fireworks- related eye injuries. Ophthalmic epidemiol, 2000; 7(2): 139148.

7. de Faber JT. Fireworks injuries treated by Dutch ophthalmologists New Year 2008/'09. Ned Tijdschr Geneeskd, 2009; 153: A507.

8. Alphonse VD, Kemper AR, Strom BT, Beeman SM, Duma SM. Mechanisms of eye injuries from fireworks. JAMA, 2012; 308(1):33-44. do: 10.1001 /jama.2012.6964

9. Smith GA, Knapp JF, Barnett TM, Shields BJ. The rockets' red glare, the bombs bursting in air: fireworks-related injuries to children. Pediatrics, 1996; 98 (1):1-9.

10. Alinia S, Rezaei S, Daroudi R, Hadadi M, Akbari Sari A. Extent, nature and hospital costs of fireworks-related injuries during the Wednesday Eve festival in Iran. $J$ Inj Violence Res, 2013;5(1):11-16.

11. Adeoti C. O, Bello T. O., Ashaye A. O. Blinding ocular injuries. Nig J. Surg. Sci, 2004; 14 (2): 4446.

12. Mohammadi SF, Zandian M, Fakhraie G, Majdi M, Tabatabai SA, Rahnama A, Lashay A. Ultrasound biomicroscopy findings in fireworks-related blunt eye injuries. Eur J Ophthalmol, 2012; 22(3):342348.

13. Chan WC, Knox FA, McGinnity FG, Sharkey JA. Serious eye and adnexal injuries from fireworks in Northern Ireland before and after lifting of the firework ban--an ophthalmology unit's experience. Int Ophthalmol, 2004; 25(3):167-169.

14. Smittenberg MN, Lungelow D, Rode $H$, van As $\mathrm{AB}$, Millar AJ. Can fireworks-related injuries to children during festivities be prevented? S Afr Med $J, 2010 ; 100(8): 525-8$

15. Gordon YJ, Mokete M. Pediatric ocular injuries in Lesotho. Doc Ophthalmol, 1982; 53 (3):283-9.

16. Lin Y, Liang X, Liu X, Qu B, Ni Y, Jiang S, Liu Y. Prognostic factors and visual outcome for fireworks-related burns during spring festival in South China. J Burn Care Res, 2012; 33(3):e108113.

17. Singh DV, Sharma YR, Azad RV. Visual outcome after fireworks injuries. $J$ Trauma, 2005; 59 (1):109-11. 